\title{
PERFORMANCE OF THE PACKARD 2000 CA/LL AND 2250 CA/XL LIQUID SCINTILLATION COUNTERS FOR ${ }^{14} \mathrm{C}$ DATING
}

\author{
G T COOK*, D D HARKNESS** and ROBERT ANDERSON*
}

\begin{abstract}
Results are presented on the comparative characteristics of the Packard 2000 $\mathrm{CA} / \mathrm{LL}$ liquid scintillation counter with and without the low-level option on line. An initial performance assessment using ${ }^{14} \mathrm{C}$ labeled benzene with butyl-PBD as the scintillant revealed that although the background count rate decreased by approximately a factor of 3 using the lowlevel option, a substantial decrease in efficiency was also observed. However, subsequent investigations have indicated that, by careful manipulation of both scintillant composition and concentration, this loss in efficiency can largely be overcome with little or no concurrent increase in background count rate. The introduction of an active vial sample holder and a new light-guide system proved to be significant advances on the standard $2000 \mathrm{CA} / \mathrm{LL}$.
\end{abstract}

\section{INTRODUCTION}

Liquid scintillation counters are generally used in bio-medical research because of the widespread applications of $\beta$-emitting radioisotopes. The counters are produced relatively inexpensively and in large numbers. Their features are not ideally suited to low-level counting applications such as ${ }^{14} \mathrm{C}$ dating, groundwater $\left({ }^{3} \mathrm{H}\right)$ dating and general environmental monitoring for contamination from nuclear industry.

Genuine low-level scintillation counters, a more recent innovation, generally employ anticoincidence (active) shields as well as perhaps more massive passive shielding to reduce background count rates, enabling improved signal-background ratios which are acceptable for low-level applications.

The Packard $2000 \mathrm{CA} / \mathrm{LL}$ liquid scintillation counter brings a completely novel approach to scintillation counting, providing low-level counting with relatively inexpensive systems that require no active or enhanced passive shielding nor special laboratory conditions. The $2000 \mathrm{CA} /$ LL approach is to discriminate unquenchable background events (which represent ca $2 / 3$ of the total background) from organic scintillation events (quenchable) (which represent the remaining 1/3 background events) together with genuine $\beta$ disintegrations from the sample by means of pulse shape/duration analysis. A major criticism of this counter is that, although the background count rate is significantly reduced, so also is efficiency. Polach et al (1988) concluded that the optimum ${ }^{14} \mathrm{C}$ efficiency obtainable from the Packard $2000 \mathrm{CA} / \mathrm{LL}$ for a $3 \mathrm{ml}$ geometry was $54.3 \%(1.01 \mathrm{cpm}$ background) in a standard $7 \mathrm{ml}$ slimline glass vial, while an efficiency of $76.4 \%$ ( $0.21 \mathrm{cpm}$ background) was achievable from the Pharmacia-Wallac Quantulus using a $3 \mathrm{ml}$ teflon/copper vial.

\footnotetext{
${ }^{*} \mathrm{G}$ U Radiocarbon Dating Laboratory

**NERC Radiocarbon Dating Laboratory, Scottish Universities Research \& Reactor Centre, East Kilbride, Scotland
} 
Since the Packard concept depends totally on discriminating short-duration true $\beta$ events $(1-2 \mathrm{n}$ sec) from longer duration non-quenchable background events (up to $5 \mu \mathrm{sec}$ ) (van Cauter, 1986), then it would seem logical that a proportion of the true $\beta$ events are being rejected because their pulse widths are greater than the cut-off threshold defined within the software. Other than reprogramming this discrimination software, the most obvious possibility for regaining the observed losses in efficiency would be to sharpen the pulse widths from true $\beta$ events.

\section{EXPERIMENTAL}

Two ${ }^{14} \mathrm{C}$ benzene standards were used during this study. The first, of $178.5 \pm 2.0 \mathrm{dpm} \cdot \mathrm{g}^{-1}$ activity, was prepared at SURRC. The second was that used by Polach et al (1988) and corresponds to $25.7 \pm 0.2 \mathrm{dpm} \cdot \mathrm{g}^{-1}$; this already contains $15 \mathrm{mg} . \mathrm{g}^{-1}$ butyl-PBD (2-(4-Biphenylyl)-5-(4-tert-Butylphenyl)-1,3,4-Oxadiazole). The first stage in this experimental program was to establish optimum concentrations of the primary scintillants butyl-PBD and PPO (2,5 Diphenyloxazole). The criteria for establishing optimum concentrations were constancy of efficiency as measured on a $0-156 \mathrm{keV}$ window and constancy of quenching obtained from the t-SIE value. t-SIE is the spectral index of the transformed Compton spectrum of the external standard. The t-SIE range is $0-1000$, a value of 1000 indicating no quenching. The study by Polach et al (1988) used butyl-PBD at both $6.8 \mathrm{mg} \cdot \mathrm{g}^{-1}$ as recommended by Packard for the $2000 \mathrm{CA} / \mathrm{LL}$ and $17.1 \mathrm{mg} \cdot \mathrm{g}^{-1}$, presumably an optimum for the Quantulus.

Second, these optima were assessed in the presence of the secondary scintillants, bis-MSB (p-bis-( $\sigma$-Methylstyryl)-Benzene), POPOP (1,4-bis[2-(5-Phenyloxazolyl)]-Benzene), and dimethyl POPOP ( $\mathrm{Me}_{2}$ POPOP) (1,4-bis-[2-(4-Methyl-5-Phenyloxazolyl)]-Benzene; bis-MSB was also assessed alone.

Third, the second of the two ${ }^{14} \mathrm{C}$ standards $\left(25.7 \mathrm{dpm} \cdot \mathrm{g}^{-1}\right.$ containing butyl-PBD) was reassessed, both in its original form and with the most effective secondary scintillant, to determine the optimum $E^{2} / B$ and No/ $/ B$ values. The lower discriminator was kept at the ca $100 \%{ }^{3} \mathrm{H}$ cut-off point and no higher. Subsequently, this sample was then assessed in conjuction with an active plastic scintillator vial holder and, finally, in the Packard 2250 $\mathrm{CA} / \mathrm{XL}$ counter with a new plastic scintillator light-guide system. Finally, a selection of scintillant combinations were assessed in parallel in the 2000 $\mathrm{CA} / \mathrm{LL}$ and $2250 \mathrm{CA} / \mathrm{XL}$ counters for efficiency, quenching and background on a $0-156 \mathrm{keV}$ window. Stages 1,2 and 4 were carried out using $4.5 \mathrm{~g}$ benzene in a standard $20 \mathrm{ml}$ screw-cap glass vial (Packard). Stage 3 employed the corresponding $7 \mathrm{ml}$ slimline vial. Counting times for the higher activity standard were typically 100 mins, yielding an overall efficiency error of $<0.4 \%$. Background counting times were typically 500-1000 min, while for the low activity standard, $>300 \mathrm{~min}$. 


\section{RESULTS AND DISCUSSION}

Table 1A shows that, in the low-level counting mode, open-window efficiency decreases from $84.1 \%$ to $74.8 \%$ as the concentration of butylPBD increases from $2-14 \mathrm{mg} \cdot \mathrm{g}^{-1}$. In parallel, however, quenching, as reflected by the t-SIE value, decreases with increasing scintillant concentration $\left(2-12 \mathrm{mg} . \mathrm{g} \cdot{ }^{-1}\right)$. In the conventional counting mode, the trend in t-SIE value is identical but efficiency is constant (ca 93\%) from $4-20 \mathrm{mg} \cdot \mathrm{g}^{-1}$. Although $6.8 \mathrm{mg} . \mathrm{g}^{-1}$ butyl-PBD is recommended by Packard, the results presented here indicate that this is far from optimum. The loss in efficiency is not perhaps as great as with higher scintillant concentrations; however, it is within a region of both quenching and efficiency instability as reflected by the major influence of scintillant concentration on both the t-SIE and efficiency values. The results presented here indicate that a minimum of $12 \mathrm{mg} . \mathrm{g}^{-1}$ is required for stable counting conditions; however, efficiency is reduced by ca $18-20 \%$ compared to the conventional counting mode. Table 1B likewise indicates spectral stability for PPO at ca $5.6 \mathrm{mg} \cdot \mathrm{g}^{-1}$, while the loss in counting efficiency is much less than for butyl-PBD (ca 10\%).

The addition of the secondary scintillants, POPOP and $\mathrm{Me}_{2}$ POPOP (Table 2) had no influence on counting efficiency in conjuction with PPO in the low-level counting mode, while in conjunction with butyl-PBD, they improved efficiency only marginally (ca $4 \%$ ) (Table 3 ). The addition of bisMSB increased the efficiency obtainable from both PPO and butyl PBD (Tables 2, 3), enabling low-level counting efficiencies of $88-90 \%$ compared

TABLE 1

Influence of the concentration of the primary scintillants butyl-PBD and PPO on ${ }^{14} \mathrm{C}$ spectral stability and counting efficiency with and without the low-level option on line

\begin{tabular}{|c|c|c|c|c|c|}
\hline $\begin{array}{c}\text { Scintillant } \\
\left(\mathrm{mg} \cdot \mathrm{g}^{-1} \text { of } \mathrm{C}_{6} \mathrm{H}_{6}\right.\end{array}$ & $\begin{array}{l}\text { Eff }(\%) \\
L_{L}^{*} \text { on }\end{array}$ & $\begin{array}{l}\mathrm{t}-\mathrm{SIE}^{* *} \\
\mathrm{~L} \mathrm{~L} \text { on }\end{array}$ & $\begin{array}{l}\text { Eff }(\%) \\
\text { L L off }\end{array}$ & $\begin{array}{c}\mathrm{t}-\mathrm{SIE} \\
\mathrm{L} \mathrm{L} \text { off }\end{array}$ & $\begin{array}{c}\text { Difference } \\
\text { in } \% \text { eff }\end{array}$ \\
\hline \multicolumn{6}{|l|}{ A. Butyl-PBD } \\
\hline 2 & 84.1 & 557 & 91.8 & 557 & 7.7 \\
\hline 4 & 80.7 & 683 & 93.5 & 681 & 12.8 \\
\hline 6 & 78.9 & 730 & 92.8 & 732 & 13.9 \\
\hline 8 & 76.6 & 749 & 93.5 & 751 & 16.9 \\
\hline 10 & 75.7 & 757 & 93.2 & 755 & 17.5 \\
\hline 12 & 75.2 & 761 & 93.6 & 762 & 18.4 \\
\hline 14 & 74.8 & 761 & 93.1 & 760 & 18.3 \\
\hline 16 & 73.9 & 760 & 93.4 & 759 & 19.5 \\
\hline 18 & 73.5 & 758 & 93.0 & 759 & 19.5 \\
\hline 20 & 73.7 & 755 & 93.8 & 755 & 20.1 \\
\hline \multicolumn{6}{|l|}{ B. PPO } \\
\hline 2.2 & 85.4 & 582 & 92.5 & 579 & 7.1 \\
\hline 3.3 & 84.8 & 620 & 91.7 & 614 & 6.9 \\
\hline 4.4 & 84.0 & 635 & 92.8 & 629 & 8.8 \\
\hline 5.6 & 83.6 & 639 & 93.5 & 635 & 9.9 \\
\hline 7.8 & 82.8 & 638 & 92.6 & 634 & 9.8 \\
\hline 10.0 & 82.3 & 634 & 92.6 & 629 & 10.3 \\
\hline
\end{tabular}

\footnotetext{
*Low-level option $=$ pulse shape discriminator

**Spectral index of external standard
} 
TABLE 2

Effect of incorporating varying concentrations of secondary scintillants (POPOP, $\mathrm{Me}_{2}$ POPOP, and bis-MSB) into a fixed concentration of PPO (5.6mg.g $\mathrm{g}^{-1}$ of $\mathrm{C}_{6} \mathrm{H}_{6}$ )

\begin{tabular}{|c|c|c|c|c|c|}
\hline $\begin{array}{c}\text { Secondary } \\
\text { scintillant } \\
\text { (mg. } \mathrm{m}^{-1} \text { of } \mathrm{C}_{6} \mathrm{H}_{6}\end{array}$ & $\begin{array}{l}\text { Eff }(\%) \\
\text { L L on }\end{array}$ & $\begin{array}{l}\text { t-SIE } \\
\text { L L on }\end{array}$ & $\begin{array}{l}\text { Eff }(\%) \\
\text { L L off }\end{array}$ & $\begin{array}{c}\text { t-SIE } \\
\text { L L off }\end{array}$ & $\begin{array}{c}\text { Difference } \\
\text { in } \% \text { eff }\end{array}$ \\
\hline \multicolumn{6}{|l|}{ A. POPOP } \\
\hline 0 & 83.6 & 639 & 93.5 & 635 & 9.9 \\
\hline 0.1 & 83.9 & 652 & 93.5 & 651 & 9.6 \\
\hline 0.2 & 82.9 & 661 & 93.8 & 659 & 10.0 \\
\hline 0.7 & 81.9 & 696 & 93.8 & 696 & 11.9 \\
\hline 1.1 & 82.0 & 694 & 93.4 & 688 & 11.4 \\
\hline \multicolumn{6}{|l|}{ B. $\mathrm{Me}_{2}$ POPOP } \\
\hline 0.1 & 83.2 & 615 & 92.8 & 613 & 9.6 \\
\hline 0.2 & 82.3 & 632 & 93.4 & 630 & 11.1 \\
\hline 0.7 & 82.6 & 653 & 93.6 & 652 & 11.0 \\
\hline 1.1 & 82.4 & 671 & 92.7 & 663 & 10.3 \\
\hline \multicolumn{6}{|l|}{ C. Bis-MSB } \\
\hline 0.2 & 85.4 & 661 & 93.0 & 659 & 7.6 \\
\hline 0.7 & 87.5 & 682 & 93.1 & 682 & 5.6 \\
\hline 1.3 & 88.0 & 695 & 93.8 & 696 & 5.8 \\
\hline 2.7 & 89.6 & 702 & 93.7 & 699 & 4.1 \\
\hline 5.3 & 89.1 & 672 & 93.7 & 678 & 4.6 \\
\hline
\end{tabular}

TABLE 3

Effect of incorporating varying concentrations of secondary scintillants (POPOP, $\mathrm{Me}_{2}$ POPOP, and bis-MSB) into a fixed concentration of butyl-PBD (12mg. $\mathrm{g}^{-1}$ of $\mathrm{C}_{6} \mathrm{H}_{6}$ )

\begin{tabular}{cccccc}
\hline $\begin{array}{c}\text { Secondary } \\
\text { scintillant } \\
\text { (mg.g } \text { of }_{6} \mathrm{H}_{6}\end{array}$ & $\begin{array}{c}\text { Eff }(\%) \\
\text { L L on }\end{array}$ & $\begin{array}{c}\text { t-SIE } \\
\text { L L on }\end{array}$ & $\begin{array}{c}\text { Eff }(\%) \\
\text { L L off }\end{array}$ & $\begin{array}{c}\text { t-SIE } \\
\text { L L off }\end{array}$ & $\begin{array}{c}\text { Difference } \\
\text { in \% eff }\end{array}$ \\
\hline A. POPOP & & & & & \\
0 & 74.6 & 760 & 94.0 & 762 & 19.4 \\
0.1 & 76.6 & 767 & 94.5 & 768 & 17.9 \\
0.2 & 76.3 & 770 & 93.7 & 770 & 17.4 \\
0.7 & 78.7 & 767 & 93.2 & 766 & 14.5 \\
1.1 & 78.8 & 759 & 94.0 & 759 & 15.2 \\
B. $\mathrm{Me}_{2}$ POPOP & & & & & \\
0 & 75.1 & 755 & 93.5 & 755 & 18.4 \\
0.2 & 75.6 & 732 & 93.6 & 734 & 18.0 \\
0.7 & 77.2 & 726 & 93.5 & 726 & 16.3 \\
1.3 & 78.1 & 726 & 94.0 & 725 & 15.9 \\
2.7 & 78.8 & 715 & 93.5 & 717 & 14.7 \\
C. Bis-MSB & & & & & \\
0 & 74.7 & 757 & 93.3 & 754 & 18.9 \\
0.2 & 81.1 & 752 & 93.5 & 755 & 12.4 \\
0.7 & 83.9 & 752 & 93.9 & 750 & 10.0 \\
1.3 & 86.6 & 743 & 93.6 & 740 & 7.0 \\
2.0 & 87.4 & 734 & 93.5 & 732 & 6.1 \\
2.7 & 87.4 & 722 & 93.2 & 718 & 5.8 \\
3.3 & 88.0 & 708 & 93.3 & 707 & 5.3 \\
4.0 & 88.5 & 696 & 93.1 & 695 & 4.6 \\
4.7 & 87.2 & 680 & 92.7 & 681 & 5.5 \\
5.3 & 88.0 & 679 & 93.6 & 683 & 4.6 \\
\hline
\end{tabular}


TABLE 4

Influence of the concentration of the secondary scintillant bis-MSB alone on ${ }^{14} \mathrm{C}$ spectral stability and counting efficiency with and without the low-level option on line

\begin{tabular}{cccccc}
\hline $\begin{array}{c}\text { bis-MSB } \\
\left(\mathrm{mg} \cdot \mathrm{g}^{-1} \text { of } \mathrm{C}_{6} \mathrm{H}_{6}\right)\end{array}$ & $\begin{array}{c}\text { Eff }(\%) \\
\text { L L on }\end{array}$ & $\begin{array}{c}\text { t-SIE } \\
\text { L L on }\end{array}$ & $\begin{array}{c}\text { Eff }(\%) \\
\text { L L off }\end{array}$ & $\begin{array}{c}\text { t-SIE } \\
\text { L L off }\end{array}$ & $\begin{array}{c}\text { Difference } \\
\text { in \% eff }\end{array}$ \\
\hline 0.7 & 87.2 & 383 & 89.1 & 382 & 1.9 \\
1.3 & 88.9 & 533 & 91.6 & 532 & 2.7 \\
2.7 & 89.0 & 602 & 91.8 & 602 & 2.8 \\
5.3 & 88.5 & 637 & 93.0 & 637 & 4.5 \\
\hline
\end{tabular}

TABLE 5

Progressive optimization of the Packard low-level counting system using an improved scintillant, a plastic scintillant vial holder, and a new plastic scintillant light guide system ( $3 \mathrm{ml}$ geometry in slimline glass vial)

\begin{tabular}{lcccr}
\hline Counting conditions & Background & Eff(\%) & $\mathrm{E}^{2} / \mathrm{B}$ & $\mathrm{No} / \sqrt{\mathrm{B}}$ \\
\hline 1) $\begin{array}{l}\text { Butyl-PDB }\left(17.1 \mathrm{mg} \cdot \mathrm{g}^{-1}\right) \text { in Packard } \\
\text { 2000 CA/LL }\end{array}$ & 1.03 & 52.5 & 2680 & 16.8 \\
2) $\begin{array}{l}\text { Butyl-PBD }\left(17.1 \mathrm{mg} \cdot \mathrm{g}^{-1}\right) \text { with bis-MSB } \\
\left(1.1 \mathrm{mg} \cdot \mathrm{g}^{-1}\right) \text { in Packard 2000 CA/LL }\end{array}$ & 1.25 & 63.8 & 3250 & 18.5 \\
3) $\begin{array}{l}\text { As in 2) with plastic vial holder } \\
\text { in Packard 2000 CA/LL }\end{array}$ & 0.92 & 66.1 & 4750 & 22.4 \\
4) $\begin{array}{l}\left.\text { Butyl-PBD (17.1mg.g }{ }^{-1}\right) \text { with bis-MSB } \\
\left(1.1 \mathrm{mg} \cdot \mathrm{g}^{-1}\right) \text { in Packard 2250 CA/XL }\end{array}$ & 0.91 & 64.6 & 4580 & 21.4 \\
5) $\begin{array}{l}\text { As in 4) with plastic vial holder } \\
\text { in Packard 2250 CA/XL }\end{array}$ & 0.83 & 65.5 & 5170 & 22.7 \\
\hline
\end{tabular}

with $93-94 \%$ under conventional conditions. Similarly, bis-MSB alone (1.3$5.3 \mathrm{mg} \cdot \mathrm{g}^{-1}$ ) (Table 4) also enabled counting efficiencies of ca $89 \%$.

When the low activity standard was reassessed as per Polach et al (1988) (Table 5), the results obtained for optimum performance were largely comparable in terms of both efficiency and background. The addition of bisMSB enabled an increase in optimum efficiency from 52.5 to $63.8 \%$ with, however, some increase in background $(1.03$ to $1.25 \mathrm{cpm}) . \mathrm{E}^{2} / \mathrm{B}$ and $\mathrm{No} / \sqrt{\mathrm{B}}$ values were nevertheless substantially increased. A further enhancement was then achieved using the active vial sample holder. By direct comparison, the Packard $2250 \mathrm{CA} / \mathrm{XL}$ produced a better overall response than the $2000 \mathrm{CA} / \mathrm{LL}$, although slightly poorer than the latter counter used in conjunction with the active vial sample holder. The $2250 \mathrm{CA} / \mathrm{XL}$ in combination with the active vial sample holder produced the best overall response.

Table 6 compares the counting characteristics of a selection of scintillant combinations in both the $2000 \mathrm{CA} / \mathrm{LL}$ and $2250 \mathrm{CA} / \mathrm{XL}$. The addi- 
TABLE 6

Comparison of efficiency, quenching, and background between the Packard $2000 \mathrm{CA} / \mathrm{LL}$ and $2250 \mathrm{CA} / \mathrm{XL}$ for several scintillant combinations

\begin{tabular}{|c|c|c|c|c|c|c|}
\hline \multirow{2}{*}{ Scintillant } & \multicolumn{3}{|c|}{$2000 \mathrm{CA} / \mathrm{LL}$} & \multicolumn{3}{|c|}{$2250 \mathrm{CA} / \mathrm{XL}$} \\
\hline & Eff $(\%)$ & t-SIE & Bkgd & Eff $(\%)$ & & Bkgd \\
\hline $12 \mathrm{mg} \cdot \mathrm{g}^{-1}$ butyl-PBD & 75.2 & 761 & 8.26 & 6.1 & 760 & 2.59 \\
\hline $\begin{array}{l}5.6 \mathrm{mg} \cdot \mathrm{g}^{-1} \text { PPO with } \\
0.7 \mathrm{mg} \cdot \mathrm{g}^{-1} \text { POPOP }\end{array}$ & 81.9 & 696 & 7.69 & 80.5 & 799 & 4.48 \\
\hline $\begin{array}{l}5.6 \mathrm{mg} \cdot \mathrm{g}^{-1} \mathrm{PPO} \text { with } \\
2.7 \mathrm{mg} \cdot \mathrm{g}^{-1} \text { bis-MSB }\end{array}$ & 89.6 & 702 & 8.74 & 89.6 & 807 & 5.20 \\
\hline $\begin{array}{l}12 \mathrm{mg} \cdot \mathrm{g}^{-1} \text { butyl-PBD } \\
\text { with } 4 \mathrm{mg} \cdot \mathrm{g}^{-1} \\
\text { bis-MSB }\end{array}$ & 88.5 & 696 & 8.68 & 88.1 & 808 & 5.34 \\
\hline $5.3 \mathrm{mg} \cdot \mathrm{g}^{-1}$ bis-MSB & 88.5 & 637 & 8.99 & 88.8 & 779 & 5.00 \\
\hline
\end{tabular}

for PBD and PPO/POPOP are significantly lower than for the other scintillants, although, as already shown, total counting efficiency also decreases. With the exception of PBD alone, there is no difference in efficiency between the two counters. The efficiency from PBD is exceptionally low $(6.1 \%)$ and is probably due to absorption of that wave length of light by the plastic scintillator. t-SIE values for PBD are unchanged, while for all other scintillants, values are increased by $>100$ units in the $2250 \mathrm{CA} / \mathrm{XL}$. From the results presented here, backgrounds for the three scintillant combinations giving optimum counting efficiency are not significantly different but show ca $40 \%$ decrease in the $2250 \mathrm{CA} / \mathrm{XL}$.

\section{CONCLUSIONS}

Our results show that the Packard $2000 \mathrm{CA} / \mathrm{LL}$ is sensitive to both scinntillant composition and concentration. However, by careful manipulation of both parameters, it is possible to obtain counting efficiencies in the lowlevel counting mode almost comparable to those from conventional counting, within $4-5 \%$, without substantially increasing the background count rate. One fact difficult to grasp is that, in some circumstances, efficiency increases as quenching increases. This obviously reflects the complexity of the pulse-shape analyses and must involve a complex balance of sufficient scintillant, self-absorption and energy transfer to scintillants capable of sharpening pulse widths. The results of this study merely touch on the work involved in optimizing this counter. Obviously, much work is required, perhaps at a much more fundamental level, eg, examining pulse shapes in relation to different scintillant compositions and then reprogramming the pulse discrimination software in light of optimized concentrations.

The introduction of the active vial sample holder and the new lightguide system are substantial advances on the original 2000/LL. Both counters represent a significant advance in ${ }^{14} \mathrm{C}$ dating by liquid scintillation and although, at present, their performance cannot match that of the Quan- 
tulus, they do have the advantage of being more routinely usable and not requiring special vials or greater passive shielding. The results for the 2250 $\mathrm{CA} / \mathrm{XL}$ were obtained within one week, the counter having been optimized within 24 hours of receipt.

\section{REFERENCES}

Polach, H, Calf, G, Harkness, D D, Hogg, A, Kaihola, L and Robertson, S, 1988, Performance of new technology liquid scintillation counters for ${ }^{14} \mathrm{C}$ dating: Nuclear Geophysics, in press.

Van Cauter, S, 1986, Three dimension spectrum analysis: a new approach to reduce background of liquid scintillation counters: Packard Applications Bull no. 006. 